\title{
Institutional Research and the Student: The Promise of Mixed Methods and Intersectional Analysis
}

Merridy Wilson-Strydom, Francois Strydom, Lana Hen-Boisen

\section{Introduction}

With the global trends of massification, marketisation and liberalisation of higher education, the increasing importance of higher education for economic development, and the acceptance of the New Public Management agenda in education there has been an intensifying need for evidence-based management, and thus, institutional researchers who are usually tasked with providing this evidence (Calderon and Mathies 2013). These increased accountability demands of higher education globally have emphasised the need for institutions to illustrate what students experience, know and can do as graduates (Coates 2014). However, Kuh, Ikenberry, Janowski, Cain, Ewell, Hutchings, and Kinzie (2015:2) warn that while accountability demands are likely to increase it is vital to remember that evidence does not "speak for itself" and requires interpretation, integration and reflection to change and improve institutions.

While institutional research (IR) has had more than a century long history in the United States (U.S.) (Reichard 2012), it is a rather newer profession in the Southern African region (Lange, Saavedra, and Romano 2013). However, IR in Southern Africa has been developing substantially over the past few decades. In South Africa, there is a strong foundation of institutional data submitted nationally in terms of the Higher Education Management Information System (HEMIS). Looking at students specifically, there is data tracking student enrolment, demographics, throughput and graduation, and this is central in HEMIS. Yet, in this chapter we argue that IR has a greater role to play in understanding the student than the reporting of HEMIS data, important as this function is.

In making this argument we draw on a meta-analysis of quantitative and qualitative institutional research data from one South African university as a case study to show the potential for evidence-based change that deeper understandings (rather than predictions) of students' engagement with and their experiences of higher education open up. Using this meta-analysis we argue for the importance of a sustained IR focus on better understanding our students, what they do at university, and their experiences both inside and outside of university, all of which, ultimately have implications for their success. We show how using mixed methods and explicitly locating institutional research within a pragmatist research paradigm takes us further towards understanding students' lives in practice. Further, we draw on the relatively new IR focus on intersectional analysis (Harper 2007; Maramba and Museus 2011; Museus and Griffin 2011) to show how multiple dimensions of students' identities such as race, gender, socioeconomic status, being a first generation student and 
so on, intersect in complex ways. In this way we seek to avoid the IR challenge Terenzini highlighted during his closing remarks at the 2012 AIR Conference - "the current sense of urgency to do something to fix things, an urgency that is pushing U.S. higher education towards developing simple solutions for complex problems" (Terenzini 2013:145, emphasis in original).

\section{Institutional research and the student}

Why should IR place particular emphasis on understanding the student? The teaching of students, together with the other focuses of universities on research and community engagement, is what makes universities unique in comparison with research institutes or other development organisations. Further, without students, higher education would have little funding base. The research conducted by the Southern African Regional Universities Association (SARUA) has shown that across the region, by far the majority of funding comes from government subsidy (which is mostly enrolment based funding) and student fees. Further, over time, the proportion of universities' income from student fees has been increasing - from 24.6\% in 2006 to 37.9\% in 2010 (Butcher, Wilson-Strydom, Hoosen, McDonald, Moore, and Barnes 2008; Wilson-Strydom and Fongwa 2012:33). Despite the critical importance of students to the project of higher education student performance remains relatively poor and insufficient to meet the skills needs of the region.

In South Africa, the major challenges of low throughput and success rates have been well documented (CHE 2012), despite the availability of high quality national level data about student enrolment, throughput and graduation. Drawing on national institutional data (HEMIS data), the Department of Higher Education and Training (DHET 2016) reported that, although there have been some improvements over the previous twelve years, the system currently shows a graduation percentage of $55.3 \%$ after seven years from year of first enrolment for qualifications that should take three years (2008 cohort). Although there has been an improvement from the $49.7 \%$ graduation percentage after seven years for the 2000 cohort, large proportions of young people do not complete their degrees, even after 10 years. The data are shown in Table 1 below.

Table 1: Cumulative national graduation \% by year (contact and distance programmes)

\begin{tabular}{|c|c|c|c|c|c|c|c|c|c|}
\multirow{2}{*}{$\begin{array}{c}\text { Intake year } \\
\text { (Year 1) }\end{array}$} & Year 3 & Year 4 & \multicolumn{1}{c|}{ Year 5 } & \multicolumn{1}{c|}{ Year 6 } & Year 7 & \multicolumn{1}{c|}{ Year 8 } & \multicolumn{2}{c|}{ Year 9 } & Year 10 \\
\cline { 2 - 10 } & 19.2 & 33.9 & 42.7 & 47.1 & 49.7 & 51.2 & 52.4 & 53.4 \\
\hline 2000 & 19.4 & 32.6 & 40.9 & 45.2 & 47.6 & 49.2 & 50.5 & 51.4 \\
\hline 2001 & 19.3 & 32.5 & 40.8 & 44.8 & 47.2 & 48.6 & 49.7 & 50.6 \\
\hline 2002 & 18.9 & 32.9 & 41.0 & 45.3 & 47.7 & 49.3 & 50.6 & 51.6 \\
\hline 2003 & 19.7 & 33.7 & 42.4 & 46.7 & 49.3 & 51.0 & 52.3 & 53.5 \\
\hline 2004 & 21.9 & 37.1 & 46.2 & 50.7 & 53.5 & 55.1 & 56.5 & 57.6 \\
\hline 2005 & 20.3 & 35.1 & 44.4 & 49.1 & 51.9 & 54.0 & 55.8 \\
\hline 2006 & 19.2 & 34.0 & 43.9 & 49.0 & 52.5 & 54.7 & & \\
\hline 2007 & 20.5 & 36.1 & 46.2 & 51.9 & 55.3 & & & \\
\hline
\end{tabular}

(DHET 2016:36) 
Partially as a result of these concerning trends as well as lessons learned during the first round of quality audits that took place from 2004-2012, the Higher Education Quality Committee's (HEQC) Quality Enhancement Project (QEP) emphasises that student learning needs to be enhanced, the number of graduates need to increase and graduates need to have attributes that are "personally, professionally and socially valuable" (Council on Higher Education 2014). Further, the major student protests (\#FeesMustFall, \#RhodesMustFall and so on) experienced in South Africa since 2015 highlight the importance of universities better understanding or 'knowing' their students - beyond the common reporting categories we typically use in the IR arena.

What does this mean for institutional research? What role could institutional research play in turning this tide of poor performance - so using evidence for positive change? One possibility, as we will show in this chapter, is for IR to explore innovative methodological approaches so moving the focus of IR data beyond quantitative tracking of student trends and predictions of performance (although, of course, these trends remain important). For example, Delaney (2008) presents the wide range of IR focused on students in the U.S. and argues for the importance of both quantitative and qualitative studies, primary and secondary data sources as well as the need for large scale studies and more fine-grained research. In a similar vein, Harper (2007:56) calls for more '[S]ophisticated understandings of how diverse populations of students navigate their ways to and through higher education', and argues that at present, 'talking and listening to students remain uncommon in institutional research.' Swing and Ross (2016) maintain that institutional research topics should 'inform decisions students make (e.g. how to best use time, academic and extracurricular choices, and life decisions that impact collegiate success) and that the timing for release and promotion of institutional research products should be 'intentionally aligned with the cycles of student decisions'.

Although Harper, Swing and Ross were writing about the U.S. context, a similar argument could be made in the Southern African region. Thus, in this chapter we seek to challenge the status quo of institutional research focused on students, and present concrete examples of how we might talk and listen to students more effectively.

\section{Intersectionality, institutional research and mixed methods}

The concept of intersectionality emerged from radical resistance politics and related theoretical positioning such as critical race theory and Black feminist theory (Crenshaw 1989; May 2015). As such, the roots of this approach are embedded in research on identity politics, and in particular critiques of how research on inter-group differences failed to take account of intra-group differences, so missing the 'multiple social identities [that] shape the lives of oppressed individuals' (Museus and Griffin 2011:6). The notion of intersectionality has been applied across multiple disciplines, thus Cho, Crenshaw, and McCall, (2013:795) argue that we should frame intersectionality as an 'analytic sensibility'; a way of thinking about and analysing a given situation. They explain this further as follows:

What makes an analysis intersectional - whatever terms it deploys, whatever its iteration, whatever its field of discipline - is its adoption of an intersectional way of thinking about the problem of sameness and difference and its relation to power. 
This framing - conceiving of categories not as distinct but as always permeated by other categories, fluid and changing, always in the process of creating and being created by dynamics of power - emphasises what intersectionality does rather than what intersectionality is (Cho et al. 2013:795; our emphasis).

\section{Intersectionality, higher education and institutional research}

Although the use of intersectionality theory is relatively new in higher education research, there is a growing body of recent research and theorising in this area (see Davis, BrunnBevel and Olive 2015; Greyerbiehl and Mitchell 2014; Jennrich and Kowalski-Braun 2104; Mitchell and Sawyer 2014; Nunez 2014; Sawyer and Palmer 2014; Tevis and Griffin 2014). Further, although the conceptual frame of intersectionality might not always be explicitly noted, many higher education studies that take account of diversity of staff and students, nonetheless, employ intersectional themes (Nunez 2014). In her comprehensive synthesis of literature on intersectionality and higher education with a particular focus on Latino students, Nunez (2014:35) poses the following research question: 'How can higher education research be expanded to incorporate attention to interlocking systems of oppressions that contribute to social reproduction of inequalities in postsecondary educational outcomes?' We might ask a similar question, but in the specific context of institutional research. Writing about IR specifically, Griffin and Museus (2011:8) note that

[T]hose employing intersectional analyses strive to better understand the unique ways in which multiple intersecting social identities come together to shape [students'] experiences, making distinctions in how individuals experience and engage in environments as a result of their unique position at particular intersections, rather than focusing on a single identity (Museus and Griffin 2011:8).

This is the broad definition of intersectionality (see also, Davis et al. 2015) that we have worked with in our intersectional analysis of students' engagement and experiences at a South African university.

Museus and Griffin (2011) argue that intersectional analyses can advance higher education research in at least four ways. Firstly, intersectional analyses potentially provide a more accurate reflection of the growing diversity of students in higher education. It is common for institutional researchers, particularly in South Africa, to disaggregate data by race and gender, however, research that looks at race and/or gender only, does not take account of the influence of other identities such as social class, nationality, sexuality, being a first-generation student and so on. Secondly, intersectional analyses provide a means of bringing out voices and realities on the margins that may be silenced when we focus on one-dimensional categories (see also Nunez 2014). For example, Tevis and Griffen (2014) highlight the absence of the voice of students with disabilities in much research on marginalised populations within higher education. Thirdly, adopting an intersectional analytic sensibility provides a means for uncovering 'how converging identities contribute to inequality' (Museus and Griffin 2011:10) and this has implications for how we target institutional interventions. 'Thus intersectional analyses can enable higher education researchers to make prudent decisions about where to invest their energy' (Museus and Griffin 2011:10). Fourthly, rich 
intersectional understandings of how multiple social identities interact helps to avoid the challenge of advancing equality in one area while perpetuating inequalities in other areas (Crenshaw 1989).

\section{Mixed methods, pragmatism and intersectional research}

Obviously, setting out to research the complex ways in which identities intersect and influence experience must have methodological implications. While intersectional research is often conducted using qualitative methods, there are also examples of quantitative and mixed methods approaches being used in the literature (Davis et al. 2015; Nunez 2014). When used in IR contexts, mixed methods are commonly advocated. There are several helpful sources on using mixed methods in institutional research more broadly, and for intersectionality analyses in particular ${ }^{1}$ on which we can draw (Griffin and Museus 2011; Harper 2011; Kolodziejczyk 2015; Maramba and Museus 2011; Museus and Griffin 2011; Pifer 2011).

Mixed methods has been argued to be a third major approach within research methodology (Johnson, Onwuegbuzie, and Turner 2007). Although debates about research methods, paradigms, epistemology and ontology are ongoing, there is a growing acceptance of mixed methods - commonly located within a pragmatist paradigm - as an alternative (Creswell and Plano Clark 2011; Teddlie and Tashakkori 2009). Pragmatism advocates for an epistemological middle ground, highlighting the similarities rather than differences across paradigms (Armitage 2007; Cherryholmes 1992; Feilzer 2010; Morgan 2007). According to a pragmatic stance 'knowledge is simultaneously constructed and based on a general reality we all inhabit' (Griffin and Museus 2011:20). For the researcher working within a pragmatist paradigm the real world research question or problem is primary and the methods are selected based on what is best suited to the issue at hand. This stance resonates well with the demands of institutional research that is always, at least to some extent, focused on addressing specific problems in the real world of a given institution(s). It also resonates well with intersectional research, providing a means for the researcher to develop both broader and deeper understandings of the multidimensional nature of identity and what this means for the lives of students (as well as lecturers, administrators etc.). Based on a comprehensive historical review of mixed methods research as well as primary research with research methods experts, Johnson et al. (2007:123, our emphasis) advance the following definition

Mixed methods research is the type of research in which a researcher or team of researchers combines elements of qualitative and quantitative research approaches (e.g., use of qualitative and quantitative viewpoints, data collection, analysis, inference techniques) for the broad purposes of breadth and depth of understanding and corroboration.

1 A 2011 edition of New Directions in Institutional Research was focused on using mixed methods for intersectionality research in higher education. 
A mixed methods study would involve mixing within a single study; a mixed method program would involve mixing within a program of research and the mixing might occur across a closely related set of studies.

In this chapter we draw on a mixed methods programme approach, where we mix methods across a set of three studies (S1, S2 and S3 - see below).

There are various ways in which mixed methods can be used for conducting intersectional studies:

1. Category comparisons - quantitative methods can be used to identify where inequalities exist across different identities, categorisations and intersections.

2. Category deconstruction - disaggregation of quantitative data to look at within group differences, which can be supported by qualitative explanatory evidence.

3. Mixed methods approaches, such as the quantification of qualitative data, can be used to expand the generalisability of qualitative findings.

4. Voice excavation - using qualitative data and analysis to bring out unique voices, often at intersection margins, which may not have been heard before. Once identified, quantitative analysis for the particular intersectional grouping can be done.

5. Disparity explanation - qualitative data can be used to explain disparities found in quantitative data, so providing a richer understanding (Griffin and Museus 2011:18-19).

However, despite the value of mixed methods intersectional research there are several challenges that must be noted. The first is the challenge of conceptual complexity (Griffin and Museus 2011). The inherent complexity of intersectional analysis is both a strength (richer understandings) and a challenge. When the integration of quantitative and qualitative analysis (mixed methods) is added to this, both the conceptual and methodological complexity is further increased. For this reason, Griffin and Museus (2011) recommend that IR consider the intersection of two or three variables only, as the inclusion of more variables can make the analysis difficult to interpret. Mixed methods intersectional analyses also require expertise in both quantitative and qualitative methods, and this has resource implications as teams of researchers are commonly needed. The literature on mixed methods highlights that mixed methods research usually requires additional resources (time, energy and money) compared to mono-methods (Teddlie and Tashakkori 2009). This challenge can be overcome to some extent by using existing data sets (such as institutional data) and complementing it with specific studies, as well as through research partnerships (as we do in this chapter).

\section{Applying these ideas in practice: An intersectional analysis of student engagement and experience}

We now move on to report on the results of a mixed methods intersectional analysis conducted at a South African university as a case study of how institutional researchers might approach research on students' experiences. We show how quantitative student engagement survey data (S1), together with qualitative data (S2 and S3) about student experiences can be used to conduct an intersectional analysis. In particular, we focus on 
data about how students report spending their time both within and outside of university to illustrate the argument. As noted above, this case study uses the mixed methods programme approach - where methods are mixed across a related set of independent studies.

\section{Methodology}

We present a meta-analysis of three-years of quantitative student engagement data (2013 $\mathrm{n}=1854 ; 2014 \mathrm{n}=2133 ; 2015 \mathrm{n}=711$ ) (S1), together with qualitative evidence (interviews, participatory workshops, visual methods) of students' experiences of transitioning to university (S2) collected in $2009(\mathrm{n}=128), 2010(\mathrm{n}=142)$, and experiences during their first and second years (S3) collected in $2014(n=40)$ and $2015(n=32)$. In the following two sections we briefly outline how the quantitative and qualitative data were collected and analysed initially as independent studies, and then describe how the intersectional metaanalysis was conducted in greater detail since this is where the methodological contribution of this chapter lies.

\section{Collecting and analysing the quantitative data (S1)}

The quantitative data were collected during three years, 2013-2015, by means of the South African Survey of Student Engagement (SASSE). The SASSE is an online survey completed by undergraduate students at South African universities, which asks students to report on the prevalence of certain effective educational activities during that specific year at university. Effective educational activities are practices that have been proven to have a positive effect on students' success (Kuh, Kinzie, Schuh, Whitt and Associates 2005:8). The aim of SASSE is to determine to what extent students are engaged in their university studies, and to conclude whether these engagement levels are conducive to student success. The SASSE data are analysed using SPSS statistical software, and analyses are performed to determine the frequency of educational activities, and to compare the average engagement of different groups of students to one another. Students are also asked to report on their time spent on various academic and non-academic activities, and also to indicate their demographic profile, including their race, gender, age, generation status, home language and so on. The race question includes multiple categories representing several race classifications. However, a number of the race categories are represented by a small portion of the sample, and therefore are grouped together in order to be statistically viable. The race category is therefore recoded to three categories namely, Black, White and Other.

\section{Collecting and analysing the qualitative data (S2 and S3)}

The qualitative data were collected during two separate, but related, studies. The first study (S2), which focused on understanding students' transitions to university and first-year experiences, ran from 2009-2013, with data being collected from first-year students in 2009 and again in 2010. Data collection methods included focus group discussions and the use of visual methods where students drew a picture of their experiences of transitioning to university and provided a short written explanation. A follow-up longitudinal study (S3) involving different students was started in 2014, and runs until the end of 2016. The longitudinal study involves a cohort of students across five different fields of study, all of 
whom were first-year students in 2014. The aim of the study is to track and understand students' lives throughout their undergraduate experience. Data collection methods include an annual in-depth interview and a series of participatory workshops during which students have written short reflections on their experiences, engaged in group discussions, and used a variety of visual methods (drawing and photovoice) to explore enablers and constraints on their lives as students. For the purposes of this chapter, S3 data collected in 2014 and 2015 has been analysed.

The qualitative data from both studies was managed and analysed using NVivo software. Each participant has assigned demographic attributes, and the data were coded using both open coding and theory driven coding (Saldana 2009). The linking of demographic attributes to each data source means that each piece of qualitative data that has been coded to a specific theme can be linked back to the student's characteristics.

\section{Intersectional analysis methodology}

The intersectional analysis was carried out as a meta-analysis of the data collected across these three research projects. The initial analysis was descriptive and exploratory and involved exploring the quantitative data comparatively across student demographic categorisations and bringing the results into conversation with the qualitative findings. A series of two-way ANOVAs were run to test for significant differences using the quantitative student engagement data (S1) across two intersecting identities. Based on a review of the significant intersections emerging from these analyses and further interrogation drawing on the themes emerging from the qualitative data (S2 and S3), two quantitative intersection variables that could be used to further test for significant intersections in the quantitative student engagement data were created. Following the recommendations of Griffin and Museus (2011) to avoid working with more than three intersecting characteristics, the first variable was comprised of all possible combinations of race, gender and generational status (Table 2), and the second intersection variable was comprised of all possible combinations of race, residential status and generational status (Table 3).

Table 2: Intersection variable 1 (quantitative data)

\begin{tabular}{|c|c|c|c|c|}
\hline \multicolumn{1}{|c|}{ Race } & Gender & Generation status & Assigned value & N (S1) \\
\hline Black & Male & First & 1 & 937 \\
\hline Black & Male & Second & 3 & 1435 \\
\hline Black & Female & First & 4 & 635 \\
\hline Black & Female & Second & 5 & 112 \\
\hline White & Male & First & 6 & 129 \\
\hline White & Male & Second & 7 & 260 \\
\hline White & Female & First & 8 & 257 \\
\hline White & Female & Second & 9 & 29 \\
\hline Other & Male & First & 10 & 165 \\
\hline Other & Male & Second & 11 & 67 \\
\hline Other & Female & First & 12 & 20 \\
\hline Other & Female & Second & & 2 \\
\hline
\end{tabular}


Table 3: Intersection variable 2 (quantitative data)

\begin{tabular}{|c|c|c|c|c|}
\hline Race & Residential status & Generation status & Assigned Value & N (S1) \\
\hline Black & On campus & First & 1 & 753 \\
\hline Black & On campus & Second & 2 & 302 \\
\hline Black & Walking distance & First & 3 & 982 \\
\hline Black & Walking distance & Second & 4 & 425 \\
\hline Black & Driving distance & First & 5 & 660 \\
\hline Black & Driving distance & Second & 6 & 198 \\
\hline White & On campus & First & 7 & 96 \\
\hline White & On campus & Second & 8 & 133 \\
\hline White & Walking distance & First & 9 & 77 \\
\hline White & Walking distance & Second & 10 & 57 \\
\hline White & Driving distance & First & 11 & 201 \\
\hline White & Driving distance & Second & 12 & 201 \\
\hline Other & On campus & First & 13 & 86 \\
\hline Other & On campus & Second & 14 & 33 \\
\hline Other & Walking distance & First & 15 & 84 \\
\hline Other & Walking distance & Second & 16 & 38 \\
\hline Other & Driving distance & First & 17 & 75 \\
\hline Other & Driving distance & Second & 18 & 26 \\
\hline
\end{tabular}

A series of one way ANOVAs were then run to test for significant differences in quantitative student engagement responses across the intersection variables, so providing a composite account of how the intersection of three identity markers impacted on student engagement (S1). The trends emerging from this analysis were then further interrogated using the findings that emerged from the qualitative data. In the interests of the chapter word limit, we use just the data about how students spend their time, both on and off campus to illustrate our approach. The process followed is summarised in Figure 1 below, and elaborated on using the empirical data in the following section.

\section{Limitations}

While we argue that the methodological example we present here provides an innovative way of conducting institutional research using mixed methodology and intersectionality theory, there are some important limitations to this specific study that bear mention. The main limitation is that when the original three studies were conceptualised they were designed as standalone studies. What we have presented here is a meta-analysis across the three studies, using a mixed methods programme (as opposed to project) approach (Johnson et al. 2007:123). While we were able to draw some useful conclusions from this meta-analysis and it also provided the means of testing out the proposed methodology, future research designed for this specific purpose would be able to adopt more standard mixed methods designs, making the process simpler to follow. Regarding data analyses using the computed intersectional variables, the assumption of homogeneity was violated, and therefore the one-way ANOVAs were performed with post-hoc tests for equal variances not assumed 


\section{Three separate but related studies (Mixed methods programme approach)}

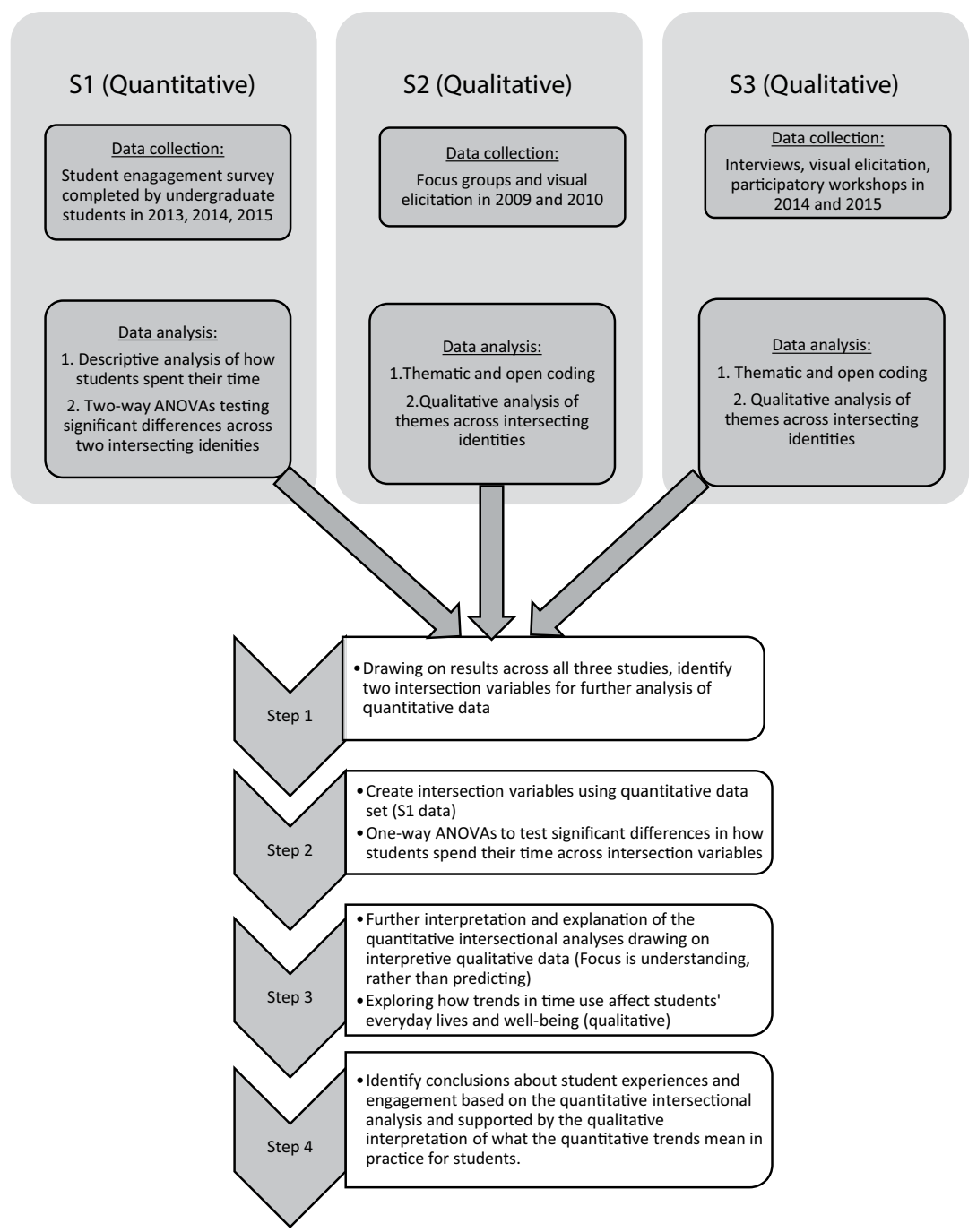

Figure 1: Mixed methods programme design

among groups (Games-Howell). These limitations notwithstanding, institutional researchers often work in complex environments and under great time pressure. Thus, testing methods that allow institutional researchers to analyse related studies that may have been conducted for a different purpose within an institution - say a PhD study for example - is in itself useful. In this way, it would not remain incumbent on resource-constrained IR offices alone to conduct the studies used to inform more detailed and nuanced understandings of students. 


\section{Going deeper: Enriching understandings of students with intersectional mixed methods}

In this section we present the empirical data to show how the intersectional understanding achieved through the quantitative analysis can be enriched when we use the qualitative data for voice excavation and deeper explanation of the data (Griffin and Museus 2011). We begin with four Figures that summarise how students report spending their time (quantitative data, S1). Each graph presents the data according to one student grouping. All four Figures follow the same general trends - with students spending most of their time attending timetabled activities, preparing for class, relaxing/socialising and travelling to class.

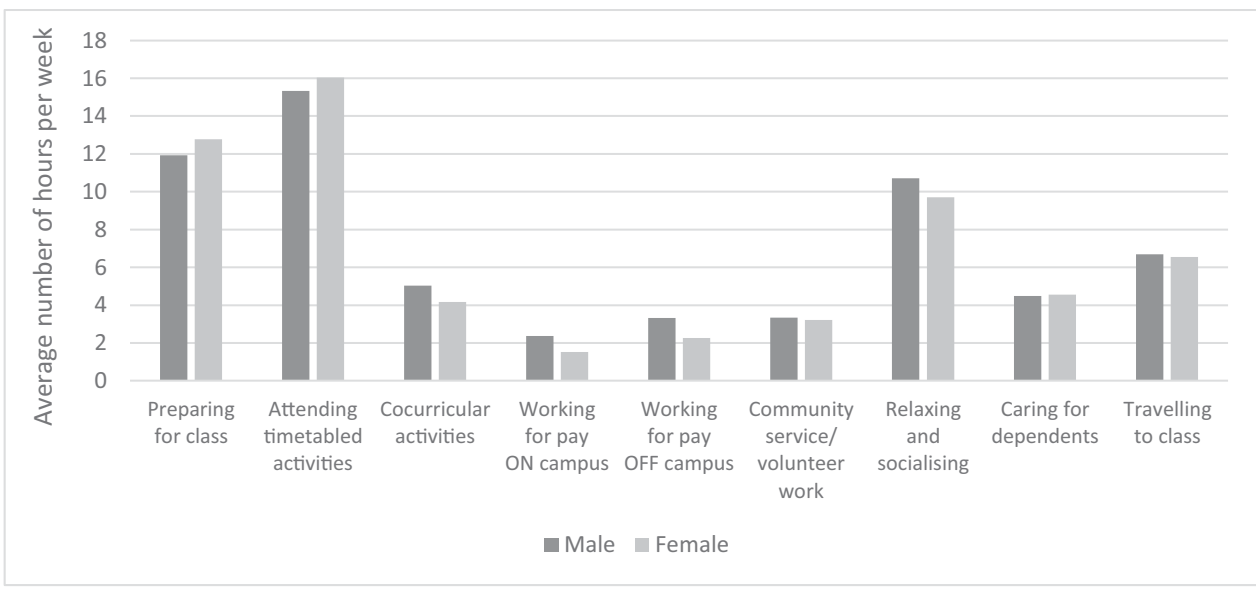

Figure 2: Estimated time spent by gender

Generally, there is relatively little difference by gender, although we see that male students spend slightly less time on academic activities and slightly more time on non-academic activities (other university activities, working, relaxing/socialising).

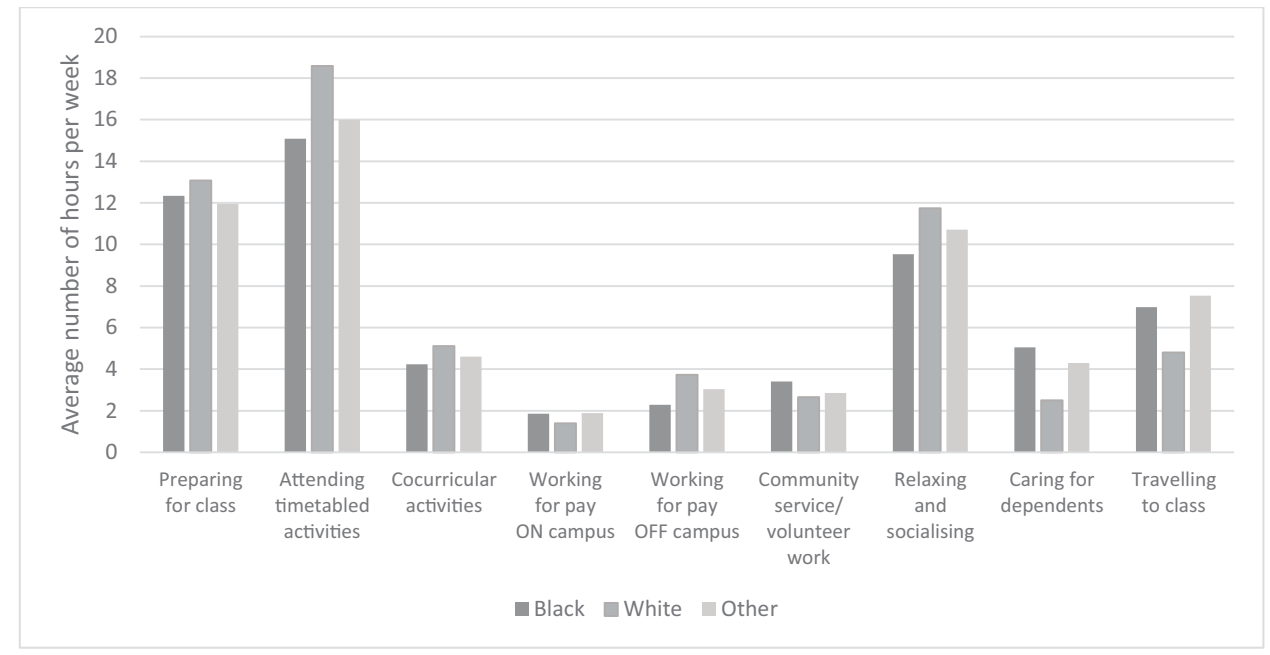

Figure 3: Estimated time spent by race 
The same general pattern is evident when we look at the data by race, although we see larger differences across the race groupings than we did with the gender groupings. From this graph we see that white students spend more time on academic activities, working for pay off campus, relaxing/socialising and less time travelling to class and caring for dependents.

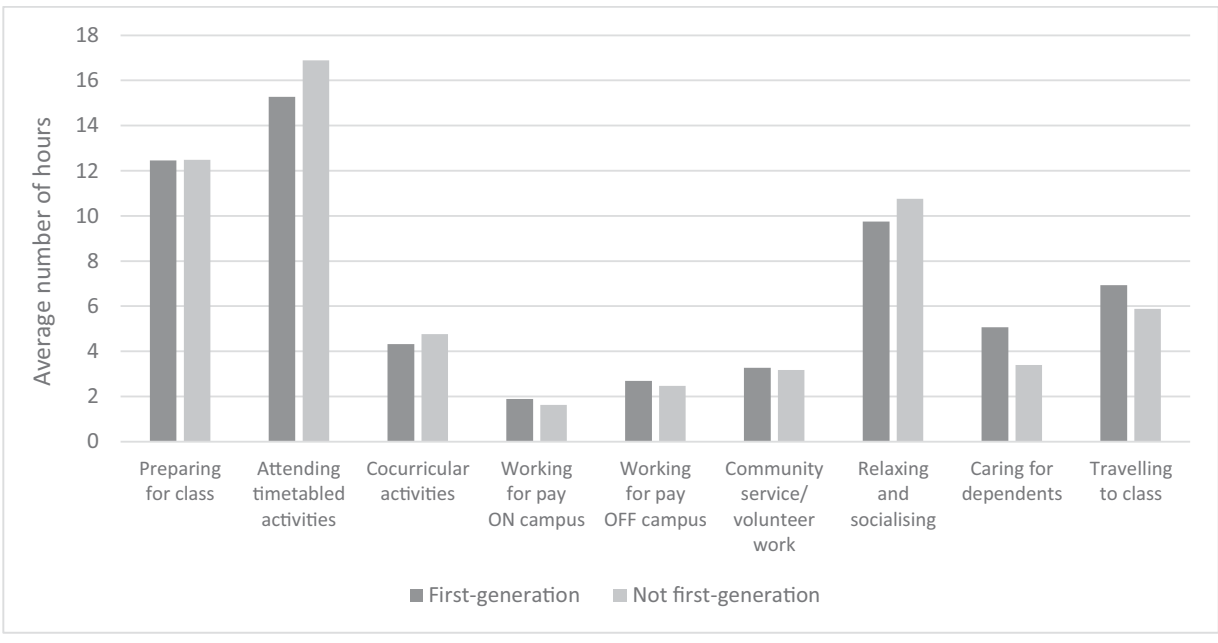

Figure 4: Estimated time spent by generational status

Once again, when we look at the data by generational status (first or second-generation) the overall pattern is the same, and we see relatively few differences across the group. Most obvious is that first-generation students spend more time caring for dependents and travelling to class. In Figure 5 we see how students spent their time based on where they live as students - their residential status. While the overall pattern remains, we see that residential status does appear to have a relatively strong influence on how students spend their time.

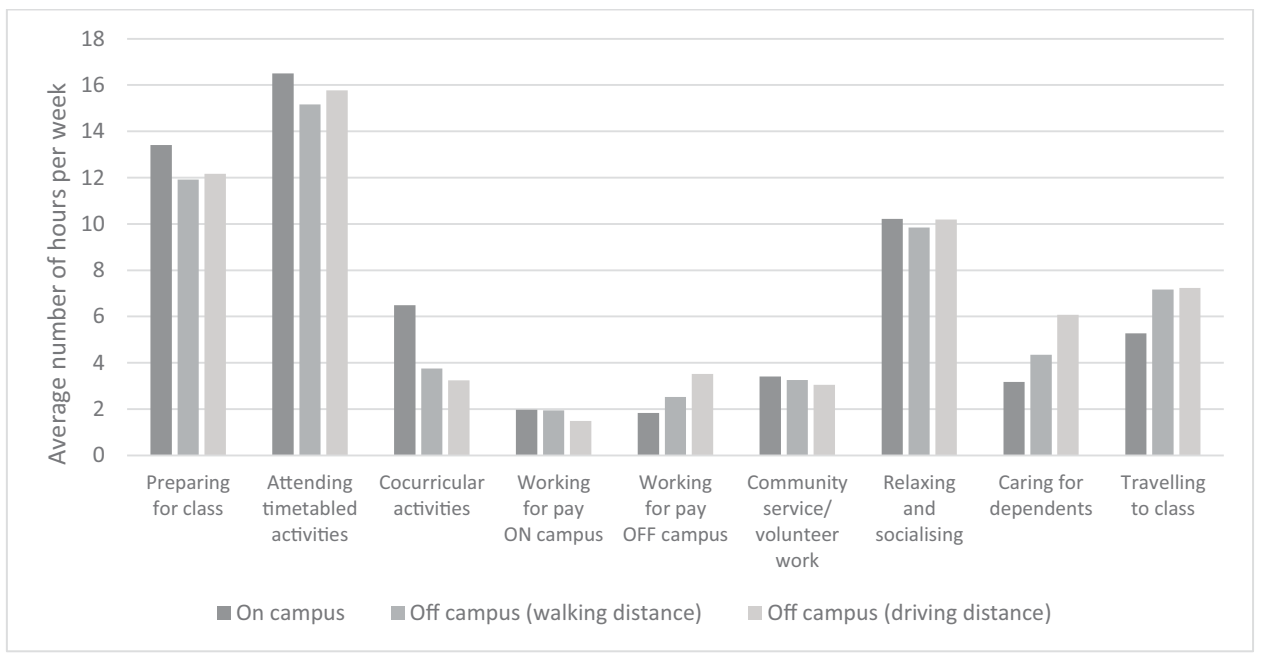

Figure 5: Estimated time spent by residential status 
Although these four figures provide us with some information about how students spend their time, it is difficult to identify particular groups who might be more or less disadvantaged in terms of how they are able to spend their time. This is where intersectional analyses are valuable. One-way ANOVAs were run for each dependent variable (time spent on different activities) with each of the two intersection variables (see Tables 1 and 2) used as the independent variables. A few illustrative examples of results are shown below, focusing on time spent attending timetabled activities, caring for dependents, travelling to and from class, and relaxing and socialising.

Figure 6 shows how time spent attending timetabled academic activities appears to be inversely related to time spent caring for dependents and travelling to and from campus. Black, female first-generation students appear to be particularly vulnerable, spending the greatest amount of time travelling and being involved in care work, and relatively less time attending timetabled activities, in comparison to the other students. We also see that collectively male students, across the groupings tend to spend more time socialising than female students, white male second-generation students spending just over 14 hours per week socialising, compared to just under 16 hours per week on timetabled activities. Black female first-generation students spend comparatively less time relaxing and socialising compared to the other student groupings.

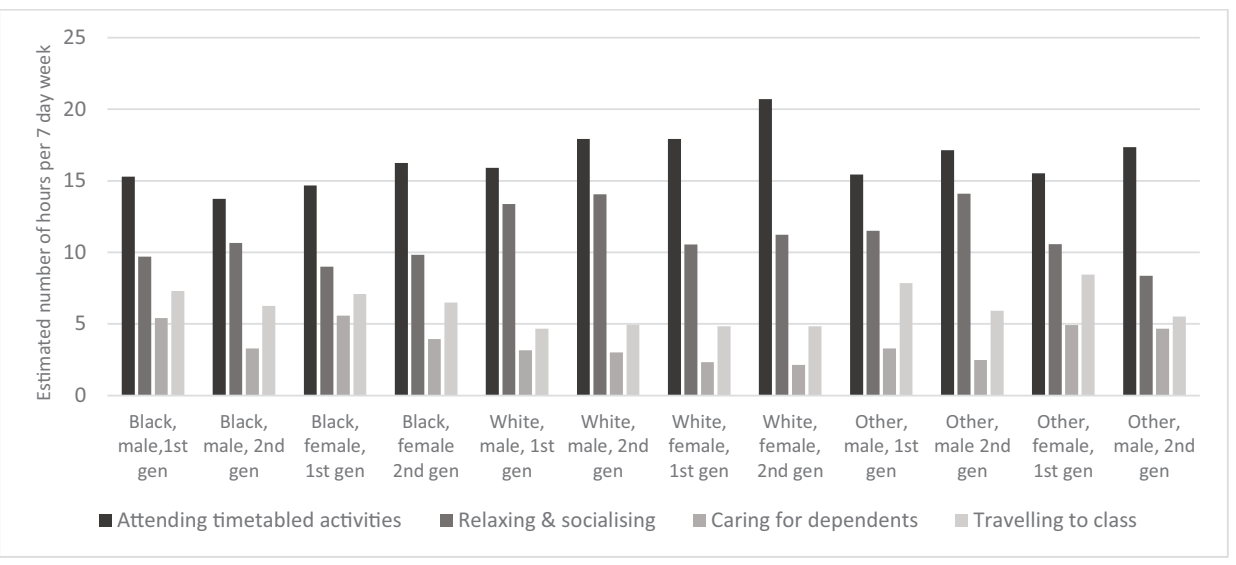

Figure 6: Time spent on selected activities by intersectional variable 1 (race, gender, generational status)

The ANOVAs showed significant differences $(p=0.000)$ in time spent attending timetabled activities between the black, female first-generation group when compared to both the white, female first and second generation groups. There was also a significant difference $(p=0.001$ and $p=0.000$ ) between the black male first-generation group and the two white female groupings. No significant differences were found for time spent attending timetabled activities when comparing black, male first and second-generation students with white male first-generation students, but a significant difference was found between male black and white second-generation students $(p=0.001)$. Overall, it is also important to note that within the student groupings, male students spend less time than female students attending timetabled academic activities and more time socialising. The ANOVAs showed that white 
male second-generation students spend significantly more time relaxing and socialising than all the other groups of students (except for white female second-generation students). White male first-generation students also spend significantly more time socialising $(p=0.001)$ compared to black female first-generation students. With respect to time spent caring for dependents, we find that black, female first-generation students spend significantly more time $(p=0.000)$ on this activity compared to black male second-generation students, black female second-generation students, white female first and second-generation students. In contrast, white female first-generation and second-generation students spend significantly less time caring for dependents $(p=0.000)$ compared to black male and female firstgeneration students.

In Figure 7 we present the same time estimation items, but analysed according to the second intersectional variable (race, residential status and generation status). We again see a clear difference by race with white students across all groupings spending more time than black students across all groupings attending timetabled activities and less time caring for dependents and travelling to and from campus. We also see that within each race and generational status grouping, the students who live on campus spend more time participating in timetabled activities, and in several cases, also spend more time relaxing and socialising.

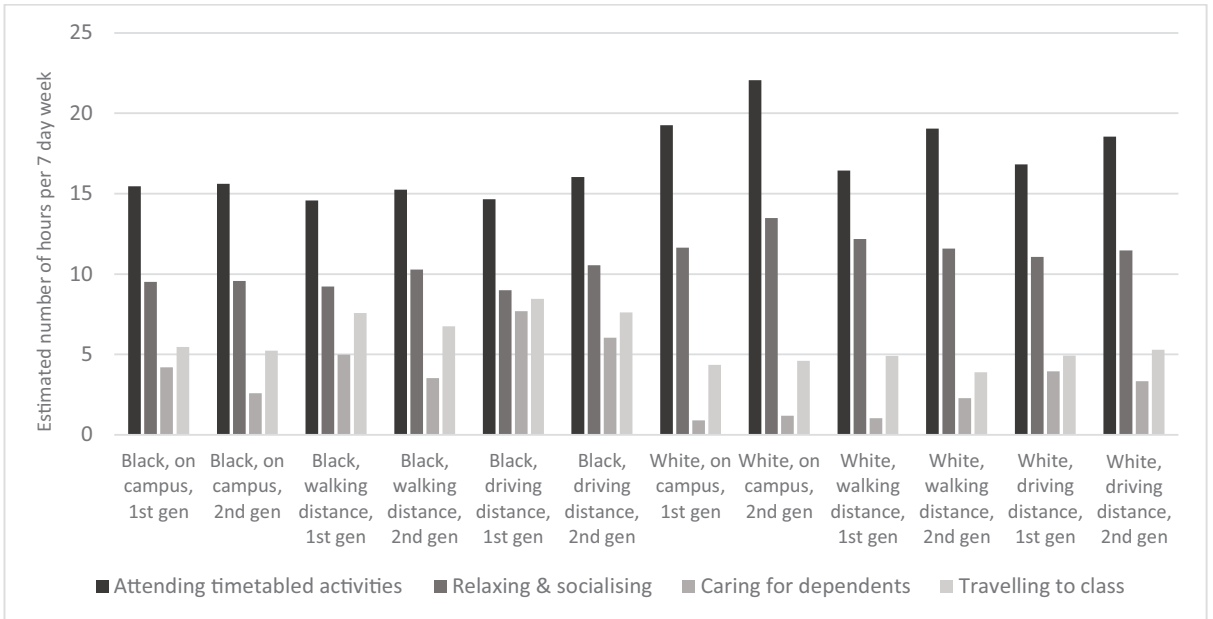

Figure 7: Time spent on selected activities by intersectional variable 2 (race, residential status, generational status) $)^{2}$

The ANOVAs show that white on campus first-generation students spend significantly more time on timetabled activities than black on campus first-generation students $(p=0.013)$, black first-generation students living in walking distance $(p=0.000)$, and black secondgeneration students living in walking distance $(p=0.010)$. White on campus secondgeneration students spend the greatest amount of time out of all the groups on timetabled activities. Significant differences $(p=0.000)$ are found when comparing this group with all the black student groupings as well as with white first-generation students who do not live

2 In Figure 7 data for all student groupings in the 'other' race category have been excluded due to the relatively small sample sizes of these categories (see Table 3). 
on campus $(p=0.000)$. Similarly, white on campus second-generation students also spend significantly more time socialising $(p<0.001)$ compared to all groupings of black students, except for black second-generation students who live within driving and walking distance from campus.

Thus, these results highlight the vulnerability of black, mostly first-generation, students who live furthest from campus. This group of students spend much longer travelling to campus each week (an average of 7 hours - see Figures 3, 4, and 5). Although we don't have socioeconomic data or information about whether students in the quantitative sample have a car, the qualitative data show that it is likely that many of the black off campus students not living in walking distance need to use public transport while white students have cars.

These numbers are powerful in and of themselves, but what they don't tell us is how this long travelling impacts on the students' daily functioning and their well-being. We can draw useful lessons from the qualitative data in this regard where it was common for students to reflect on the challenges of travel when asked to represent a typical day in their lives as students. To demonstrate this, 5 drawings (out of the sample of 40) were purposively selected as illustrative examples of how qualitative data can help us to better unpack the nuances of intersectionality. Drawings 1 and 2 were done by black students (one first-generation, and the other second-generation) who live relatively far away from campus. Drawing 1 shows how Refiloe depicts his day, with an early start of 04:30 wake up and then rush to catch the 05:30 bus. After spending a full day on campus, he catches the 19:00 bus home and arrives exhausted and unable to study. In Refiloe's interview he explained that the bus drive is one hour in each direction. He is not able to read or study on the bus as it is noisy and often over crowded.

\section{A typical day in the eife of REFILOE}

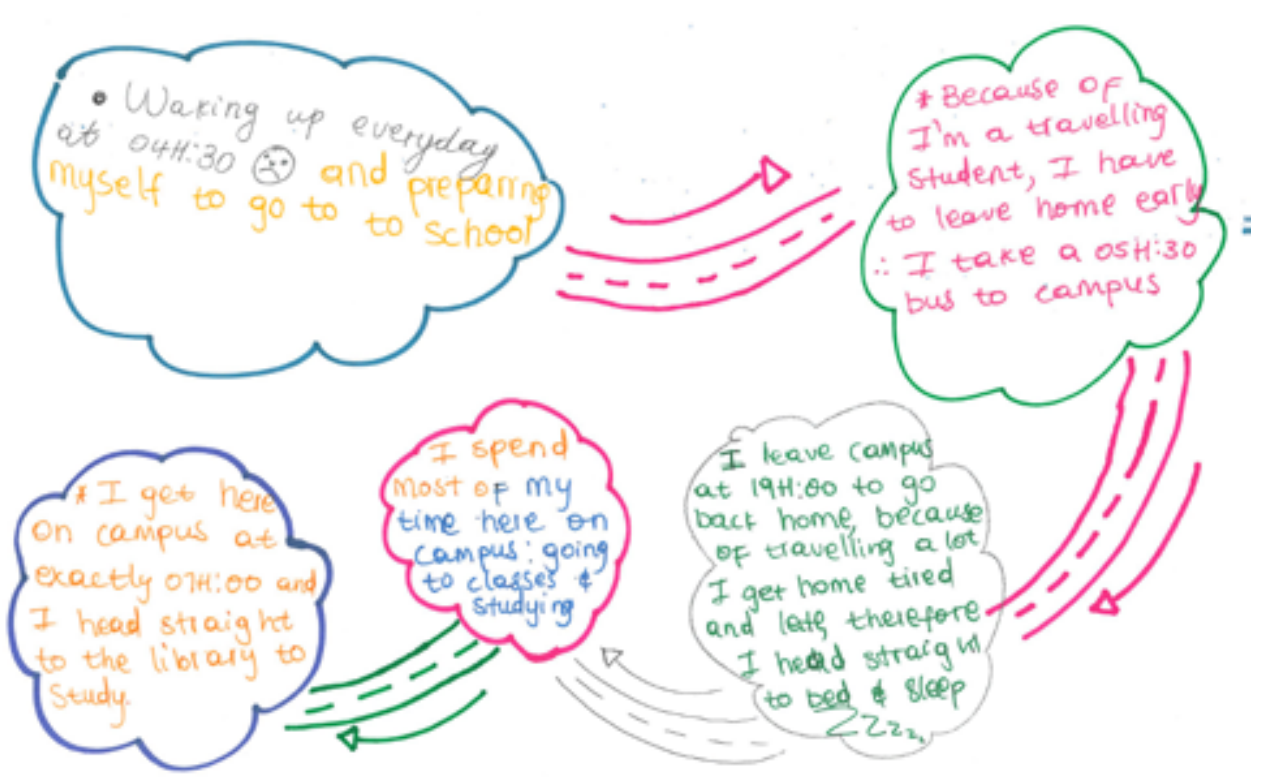

Drawing 1: A typical day in the life of a black, male, first-generation student who lives far from campus 
Drawing 2 was done by Faith, a second-generation black female student who lives far from campus. Both of Faith's parents have degrees. Her mother works as a community nurse and she has little contact with her father. As a result, finances are extremely tight and Faith needs to balance a series of part time jobs with her studies in order to make ends meet. Faith's drawing highlights the rush she faces daily to make it to campus on time, the sense of failure when she is late, and the pressure she feels to keep up appearances of coping to her family.

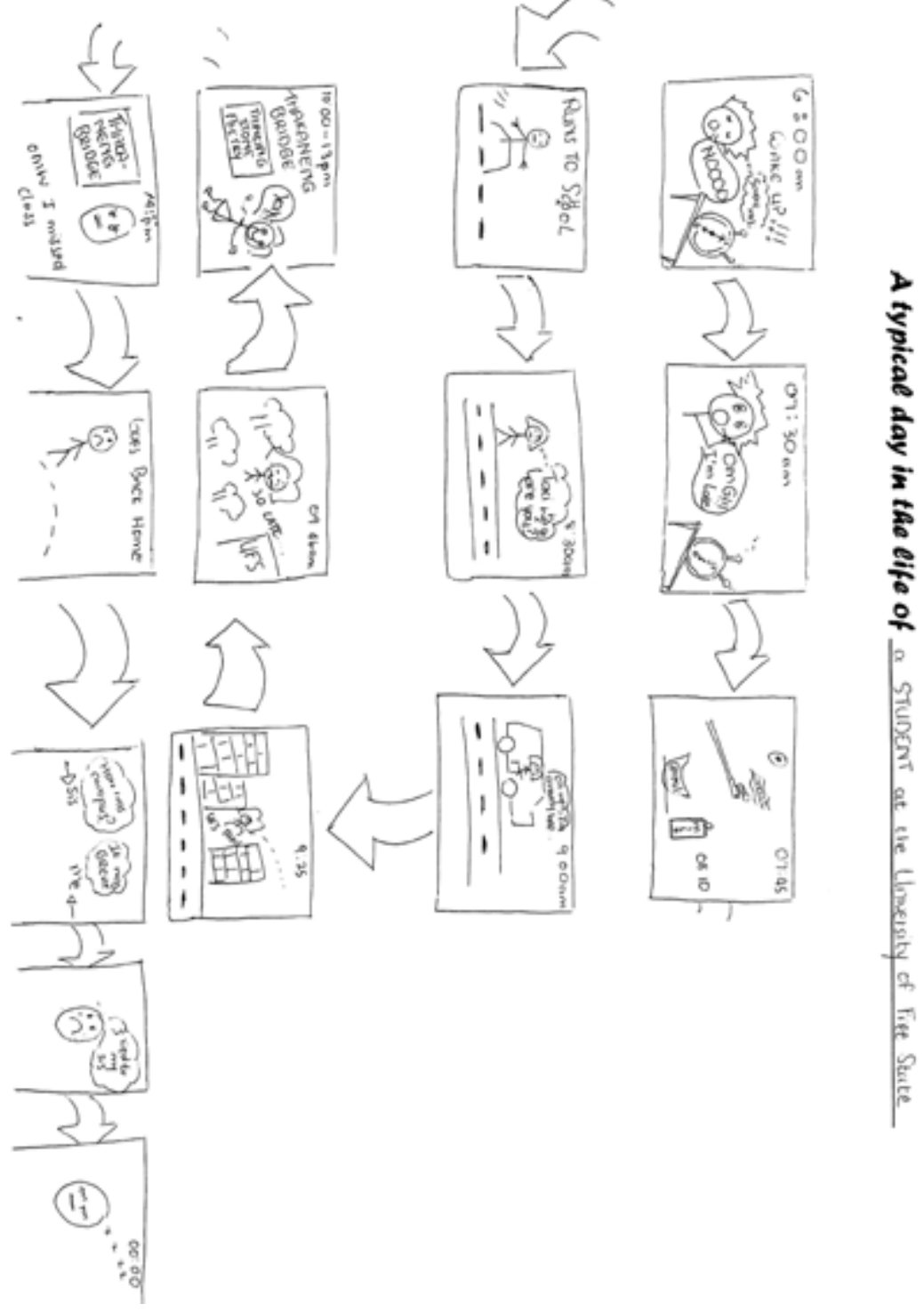

Drawing 2: A typical day in the life of a black, female, second generation student who lives far from campus

In both drawings, one is struck by the fact that much of the drawing is made up of being on the road. For students who need to travel long distances to campus, these challenges 
dominate their daily realities, rather than their academic activities on campus. This can be compared to Buhle's drawing below.

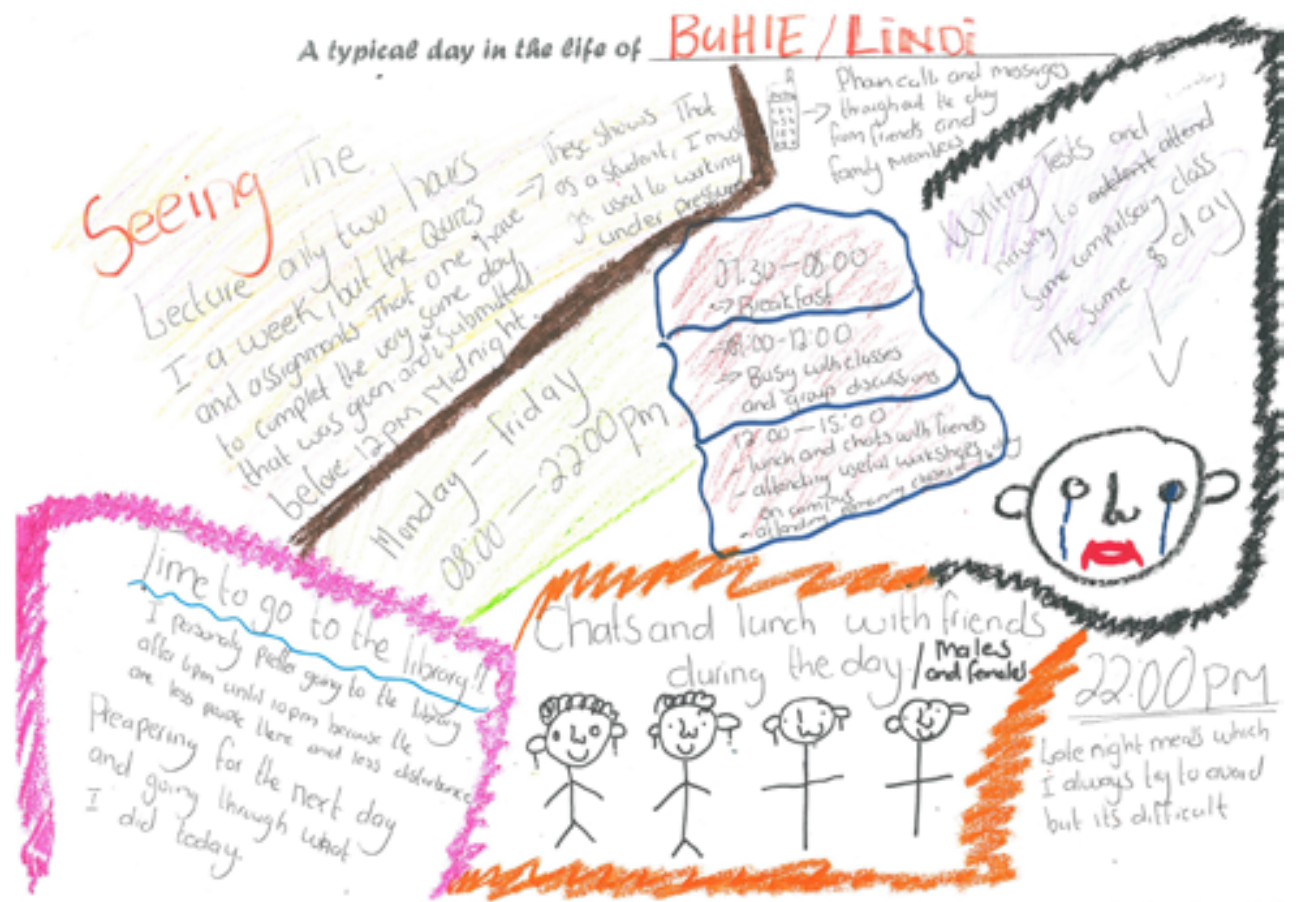

Drawing 3: A typical day in the life of a black, female first-generation student who lives on campus

Like Refiloe, Buhle is a black, first-generation student. However, unlike both Refiloe and Faith, Buhle managed to secure a place in a university residence so she lives on campus. When Buhle describes her typical day she focuses on academic work in the library, her lecturers, quizzes and assignments, her unhappiness when she needs to write tests, and socialising with friends in person and on her phone. Buhle's daily reality is thus quite different from both that of Refiloe and Faith...

In both Figures 6 and 7 we saw evidence, further confirmed by the ANOVAs, that male students - and in particular white male second-generation students - spend more time than other students socialising. This quantitative finding is also supported by the qualitative data where it was more common for male students to reflect on decisions regarding doing academic or social activities compared to female students. Two examples of drawings done by white male second-generation students are shown below. In drawing 4 we see how the student is grappling with making decisions (besluitneming) about whether to go and study for his test or to go out and party, so providing a visual illustration of the tensions evident in Figure 5 . 


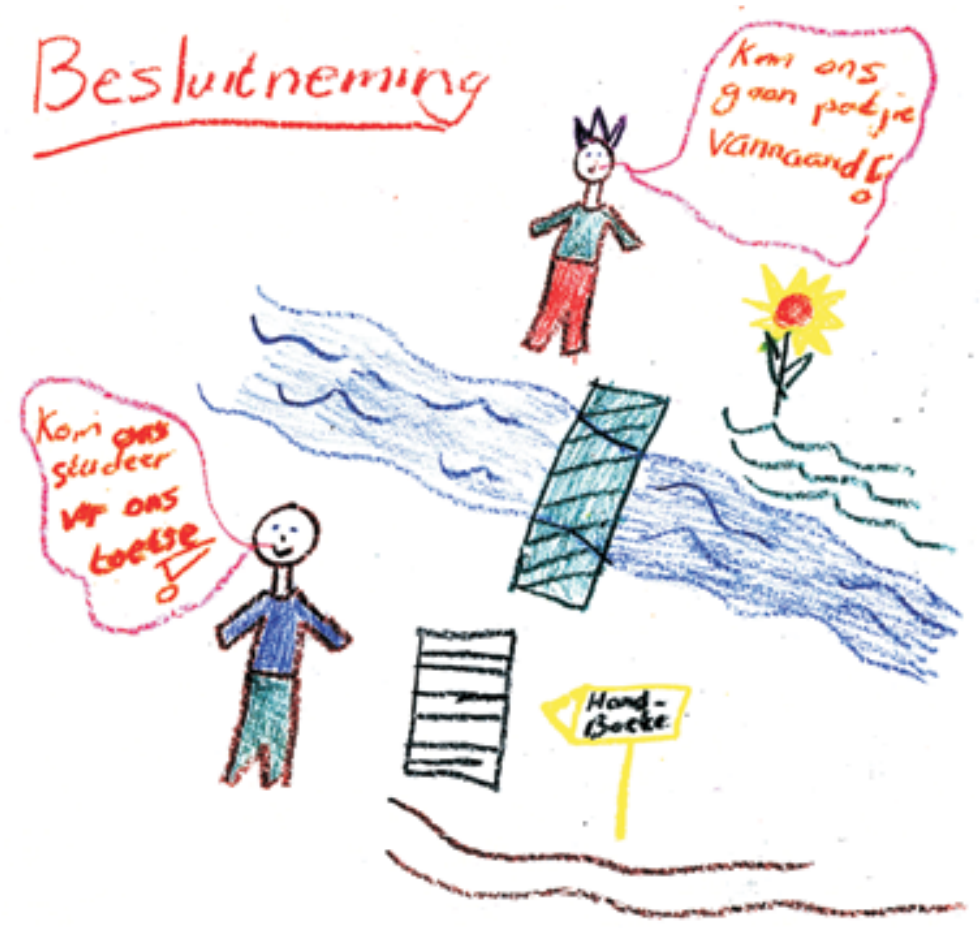

Drawing 4: White, male student, second-generation

In drawing 5 we see an example of another white male second-generation student who describes how he spends his time between sleeping, rugby, girls, and beer. In this instance, the student does not even seem to be troubled by his lack of focus on academic work.

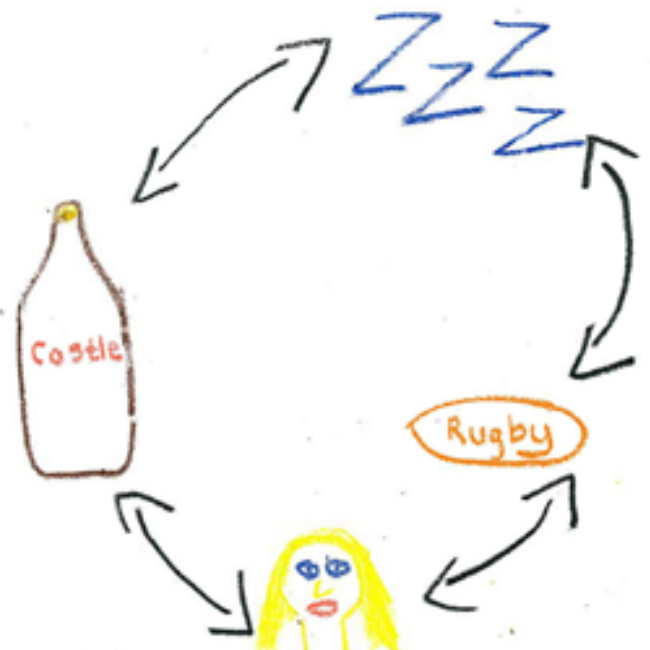

Drawing 5: White, male, second-generation 


\section{Summarising the key mixed-methods intersectional analysis findings}

Based on the mixed methods intersectional analysis demonstrated above (using only a small portion of the larger quantitative and qualitative data sets) we can identify the following three conclusions as presenting evidence for possible change:

1. Black first-generation students who live far from campus face multiple vulnerabilities in their daily lives, both within and outside of the university, that impact on how much time they can spend on academic activities, and hence are likely to undermine their academic performance.

2. These vulnerabilities are even more marked for black female first-generation students who also spend more time than their peers doing care work.

3. White male second-generation students, and particularly those who live on campus appear to find the balance between socialising and academics more difficult to manage compared to other groupings of students.

Taken together, the above three conclusions also point to the intersection between race and social class in how we think about our students. While developing specific measures of social class or socio-economic status remain a challenge in South Africa, we can use proxy measures such as generational status, time spent travelling to campus, living arrangements and requirements to care for dependents, to provide an indication of the role that social class plays in student experiences. Importantly, the main conclusions of the analysis presented here highlight just how different the challenges might be for students from differently intersecting race, class and gender backgrounds. These conclusions thus emphasise the particularities that can emerge when doing mixed-methods intersectional analyses as a core component of institutional research. We see how students whose identities intersect in multiple ways face different challenges likely to affect their academic performance. As such, more nuanced responses are required by institutions when putting in place interventions to enhance student experiences and success.

\section{Conclusion: Making intersectional evidence consequential for change}

This chapter started by outlining the complex accountability demands that higher education institutions face in the 21st century. It is clear that understanding student experiences and performance has become increasingly important to restore public confidence in higher education (Kuh et al. 2015). Yet, one of the nagging questions facing institutional researchers is how the evidence we generate can help to facilitate institutional improvement and change. In the US context researchers argue that it is vital to consider how to make evidence consequential for modifying institutional policy and practice (Kuh et al. 2015:3). Although approaches to making evidence consequential will differ in specific institutional contexts the following principles provide a useful guide:

1. Backward design - Data collection should have an end use in mind. Institutional researchers need to think about what practical questions regarding the students' experience and performance are of greatest interest to academics, support staff, decision makers and stakeholders. 
2. Identify users and design for different levels - Institutional researchers need to anticipate the levels of practice at which evidence will be used and type of data will facilitate the best understanding. We have illustrated how mixed methods and intersectional analysis can be used to present findings in a way that persuades users of the practical value of the work at their own level of practice.

3. Leverage quality assurance processes - To facilitate the use of evidence it should be aligned with institutional actions to improve student outcomes, but framed as more than compliance.

4. Connect studies to national imperatives and projects - The pressing need for deep transformation in South African higher education requires that institutional researchers are aware of the broader context and national developmental project. This awareness can provide opportunities to learn from the work of other institutions, helps to increase impact, legitimacy and the value of the evidence, and provides a crucial context understanding needed for making sense of intersectional results.

5. Link evidence to existing functions - Action and institutional improvement are more likely if (i) evidence-based decision making is a sustained practice and not episodic, (ii) institutional structures and processes provide a space in which results can be reported, implications discussed and plans made to take action and, (iii) key end users and stakeholders are engaged in the process.

6. Make evidence-based decision making a continuous process - Although evidence-based decision making is vital it is the start of a continuous cycle of institutional performance. Follow-through on decision and evaluating the impact of evidence-based change is essential to foster a culture of meaningful data use. (Kuh 2014)

The process of making evidence about student engagement and experience consequential is aimed at developing a culture of ownership rather than being defined largely by compliance with respect to student data. In a culture of ownership evidence about students' experience and performance is interpreted, integrated and reflected on to facilitate a holistic understanding from which to formulate implications for action (Kuh et al. 2015). We have shown how mixed methods and intersectional analysis provides a powerful way in which to promote such a culture.

\section{References}

Armitage, A., 2007. Mutual Research Designs: Redefining Mixed Methods Research Design. Presented at the British Educational Research Association Annual Conference, London.

Butcher, N., Wilson-Strydom, M.G., Hoosen, S., McDonald, C., Moore, A. \& Barnes, L. 2008. Chapter 2: A Profile of Higher Education in the Region, in: Kotecha, P. (ed.), Study Series 2008. Southern African Universities Association (SARUA), Johannesburg, pp. 46-124.

Calderon, A. \& Mathies, C. 2013. Institutional Research in the future: Challenges within Higher Education and the need for excellence in professional practice. New Directions for Institutional Research 2013, 77-90. http://dx.doi.org/10.1002/ ir. 20040

Council on Higher Education. 2012. Vital Stats. Public Higher Education 2010. Pretoria: Council on Higher Education (CHE).

Council on Higher Education. 2012. Overview. Quality Enhancement project. [Online]. Available: http://www.che. ac.za/focus_areas/quality_enhancement project/overview [2016, May 26]. 
Council on Higher Education. 2014. Framework for Institutional Quality Enhancement in the Second Period of Quality Assurance. Pretoria: Council on Higher Education (CHE).

Cherryholmes, C.H. 1992. Notes on Pragmatism and Scientific Realism. Educational Researcher 21:13-17. http://dx.doi. org/10.3102/0013189X021006013

Cho, S., Crenshaw, K.W. \& McCall, L. 2013. Toward a Field of Intersectionality Studies: Theory, Applications, and Praxis. Signs 38:785-810. http://dx.doi. org/10.1086/669608

Coates, H. (Ed.). 2014. Higher Education learning outcomes assessment: International perspectives. Higher Education Research and Policy (HERP). Frankfurt: Peter Lang $\mathrm{GmbH}$.

Crenshaw, K. 1989. Demarginalizing the Intersection of Race and Sex: A Black Feminist Critique of Antidiscrimination Doctorine, Feminist Theory and Antiracist Politics. University of Chicago Legal Forum 139:139-167.

Creswell, J.W. \& Plano Clark, V.L. 2011. Designing and Conducting Mixed Methods Research. Second Edition. London: Sage Publications.

Davis, D., Brunn-Bevel, R., \& Olive, J. (eds.). 2015. Intersectionality in Educational Research. Sterling, Virginia :Stylus Publishing.

Delaney, A.M. 2008. Typical Institutional Research Studies on Students: Perspective and Examples. New Directions for Higher Education 141:5768. http://dx.doi.org/10.1002/he.293

DHET, 2015. Annexure 3: Are we making progress with systemic structural transformation of resourcing, access, success, staffing and researching in higher education: What do the data say? Paper prepared for the second national Higher Education Transformation Summit. Department of Higher Education and Training. Republic of South Africa, Pretoria.

Feilzer, M.Y. 2010. Doing Mixed Methods Research Pragmatically: Implications for the Rediscovery of Pragmatism as a Research Paradigm. Journal of Mixed Methods Research 4:6-16. http://dx.doi. org/10.1177/1558689809349691
Greyerbiehl, L. \& Mitchell, D. 2014. An Intersectional Social Capital Analysis of the Influence of Historically Black Sororities on African American Women's College Experiences at a Predominantly White Institution. Journal of Diversity in Higher Education 7(4):282-294. http:// dx.doi.org/10.1037/a0037605

Griffin, K.A. \& Museus, S.D. 2011. Application of mixed-methods approaches to higher education and intersectional analyses. New Directions for Institutional Research 2011, 15-26. http://dx.doi.org/10.1002/ir.396

Harper, C.E. 2011. Identity, intersectionality, and mixed-methods approaches. New Directions for Institutional Research 2011:103-115. http://dx.doi. org/10.1002/ir.402

Harper, S.R. 2007. Using qualitative methods to assess student trajectories and college impact. New Directions for Institutional Research 2007:55-68. http://dx.doi. org/10.1002/ir.231

Jennrich, J., Kowalski-Braun, M., 2104. "My Head is Spinning": Doing Authentic Intersectional Work in Identity Centres. Journal of Progressive Policy Practice (Special Issue on Intersectionality). 2(3):199-212.

Johnson, R.B., Onwuegbuzie, A.J. \& Turner, L.A. 2007. Towards a Definition of Mixed Methods Research. Journal of Mixed Methods Research 1:112-133. http:// dx.doi.org/10.1177/1558689806298224

Kolodziejczyk, I. 2015. Mixed Methods for Study of Gender Issues in Access, Application, and Attitudes Toward ICT in Higher Education Institutions in Papua New Guinea. Sage Open 10 April 2015, 1-15. http://dx.doi. org/10.1177/2158244015581017

Kuh, G.D. 2014. Evidence-based Decision Making: Lessons Learned.

Kuh, G.D., Kinzie, J., Schuh, J.H., Whitt, E.J. \& Associates. 2005. Student success in college: Creating conditions that matter. San Francisco: Jossey-Bass.

Kuh, G.D., Ikenberry, S., Janowski, N., Cain, T., Ewell, P., Hutchings, P. \& Kinzie, J. 2015. Using evidence of student learning to improve Higher Education. San Francisco: Jossey-Bass.

Lange, L., Saavedra, F.M. \& Romano, J. 2013. Institutional Research in Emerging Countries of Southern Africa, Latin 
America, and the Middle East and North Africa: Global Frameworks and Local Practices. New Directions for Institutional Research 2013, 23-38. http://dx.doi.org/10.1002/ir.20037

Maramba, D.C. \& Museus, S.D. 2011. The utility of using mixed-methods and intersectionality approaches in conducting research on Filipino American students' experiences with the campus climate and on sense of belonging. New Directions for Institutional Research 2011, 93-101. http://dx.doi.org/10.1002/ir.401

May, V. 2015. Pursing Intersectionality, Unsettling Dominant Imaginaries. Routledge, Abingdon, United Kingdom.

Mitchell, D. \& Sawyer, D. 2014. Prefatory: Informing Higher Education Policy and Practice through Intersectionality. Journal of Progressive Policy Practice (Special Issue on Intersectionality) 2:195-198.

Morgan, D.L. 2007. Paradigms Lost and Pragmatism Regained. Methodological Implications of Combining Qualitative and Quantitative Methods. Journal of Mixed Methods Research 1:48-76. http://dx.doi. org $/ 10.1177 / 2345678906292462$

Museus, S.D. \& Griffin, K.A. 2011. Mapping the margins in higher education: On the promise of intersectionality frameworks in research and discourse. New Directions for Institutional Research 2011, 5-13. http://dx.doi.org/10.1002/ ir.395

Nunez, A.-M. 2014. Advancing an Intersectionality Framework in Higher Education: Power and Latino Postsecondary Opportunity, in: Paulson, M.B. (ed.). Higher Education: Handbook of Theory and Research. New York: Springer. 33-92. http://dx.doi. org/10.1007/978-94-017-8005-6_2
Pifer, M.J. 2011. Intersectionality in context: A mixed-methods approach to researching the faculty experience. New Directions for Institutional Research 2011:27-44. http://dx.doi.org/10.1002/ ir.397

Reichard, D. 2012. The History, Theory, and Practice of Institutional Research, in Howard, R., McLaughlin, G., Knight, W. (eds.), The Handbook of Institutional Research. Jossey-Bass, New York. 3-21.

Saldana, J. 2009. The Coding Manual for Qualitative Researchers. London: Sage Publications.

Sawyer, D. \& Palmer, R. 2014. A Different Kind of Black, But the Same Issues: Black Males and Counterstories at a Predominantly White Institution. Journal of Progressive Policy Practice (Special Issue on Intersectionality) 2:255-273.

Swing, R.L. \& Ross, L.E. 2016. Statement of Aspirational Practice for Institutional Research. Association for Institutional Research.

Teddlie, C. \& Tashakkori, A. 2009. Foundations of Mixed Methods Research. Integrating Quantitative and Qualitative Approaches in the Social and Behavioural Sciences. Sage Publications.

Terenzini, P.T., 2013. "On the Nature of Institutional Research" Revisited: "Plus ça Change... ?" Research in Higher Education 54:137-148. http://dx.doi. org/10.1007/s11162-012-9274-3

Tevis, T. \& Griffin, J. 2014. Absent Voices: Intersectionality and College Students with Physical Disabilities. Journal of Progressive Policy Practice (Special Issue on Intersectionality) 2:239-254.

Wilson-Strydom, M.G., \& Fongwa, S. 2012. A Profile of Higher Education in Southern Africa. Volume 1: A Regional Perspective. Johannesburg: Southern African Regional Universities Association (SARUA). 